\title{
Empirical Evaluation of the Genetic Similarity of Samples From Twin Registries in Australia and the Netherlands Using 359 STRP Markers
} \author{
and Nicholas G. Martin ${ }^{3}$ \\ ' Department of Genetics, University of North Carolina, Chapel Hill, North Carolina, United States of America \\ ${ }^{2}$ Department of Medical Epidemiology and Biostatistics, Karolinska Institute, Stockholm, Sweden \\ ${ }^{3}$ Queensland Institute of Medical Research, Brisbane, Australia \\ ${ }^{4}$ Department of Biological Psychology, Free University, Amsterdam, the Netherlands
}

Patrick F. Sullivan, ${ }^{1,2}$ Grant W. Montgomery, ${ }^{3}$ Jouke Jan Hottenga, ${ }^{4}$ Naomi R. Wray, ${ }^{3}$ Dorret I. Boomsma, ${ }^{4}$

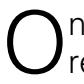
ne way to achieve the large sample sizes required for genetic studies of complex traits is to combine samples collected by different groups. It is not often clear, however, whether this practice is reasonable from a genetic perspective. To assess the comparability of samples from the Australian and the Netherlands twin studies, we estimated $F_{\text {st }}$ (the proportion of total genetic variability attributable to genetic differences between cohorts) based on 359 short tandem repeat polymorphisms in 1068 individuals. $F_{\text {st }}$ was estimated to be $0.30 \%$ between the Australian and the Netherlands cohorts, a smaller value than between many European groups. We conclude that it is reasonable to combine the Australian and the Netherlands samples for joint genetic analyses.

\section{Brief Research Note}

One of the clearest lessons from the brief history of psychiatric genetics is the critical importance of sample size. Sample size requirements have been nearly universally underestimated with the consequence that few (if any) studies in psychiatric or behavioral genetics have had adequate statistical power. However, it is equally clear that accruing large samples is both expensive and difficult to do at a single site. A potential solution is to combine samples collected by different groups; however, this practice might introduce damaging amounts of heterogeneity should groups of substantially different ancestries be combined. As an example, we now have genome-wide linkage data on cohorts from twin registries in Australia and the Netherlands - from a genetic perspective, is it reasonable to analyze these two samples jointly in order to maximize power? Therefore, we sought to estimate the degree of genetic similarity between these cohorts using empirical data.
The cohorts were ascertained from twin registries in Australia and the Netherlands following an extreme discordant and concordant design (Boomsma et al., 2000; Kirk et al., 2000). DNA samples were extracted using standard methods from whole blood in the Australian sample and from buccal epithelial brushings in the Netherlands sample. A genome-wide linkage panel (Weber16, 402 short tandem repeat polymorphisms [STRP] markers; Ghebranious et al., 2003) was genotyped in all samples by the Mammalian Genotyping Service (Marshfield Clinic Research Foundation, Marshfield, WI, NHLBI contract N01-HV-48141). Following cleaning and quality control checks, 359 STRP markers were available for analysis on 1068 individuals (519 from the Australian cohort and 549 from the Netherlands cohort) who were either genotyped pedigree founders or, if there were no genotyped founders, a randomly selected individual from that pedigree.

We used AMOVA in Arlequin (v3.01; Schneider et al., 2001) to estimate $F_{\text {st }}$ (Weir \& Hill, 2002). $F_{\text {st }}$ is the proportion of total genetic variability attributable to the genetic differences between cohorts. Based on 359 STRPs in 1068 individuals, $F_{\text {st }}$ was estimated to be $0.30 \%$ between the Australian and the Netherlands cohorts. Figure 1 places this finding in context of multiple worldwide cohorts (Rosenberg et al., 2002). Empirically, the variability between the Australian and the Netherlands cohorts was smaller than for all other samples including an European cohort $(0.7 \%)$.

Based on these findings, we conclude that it is reasonable to combine the Australian and the

\section{Received 28 May, 2006; accepted 29 May, 2006.}

Address for correspondence: Dr Sullivan, Department of Genetics, CB\#7264, 4109D Neurosciences Research Building, University of North Carolina, Chapel Hill, NC, 27599-7264, USA. E-mail: pfsulliv@med.unc.edu 


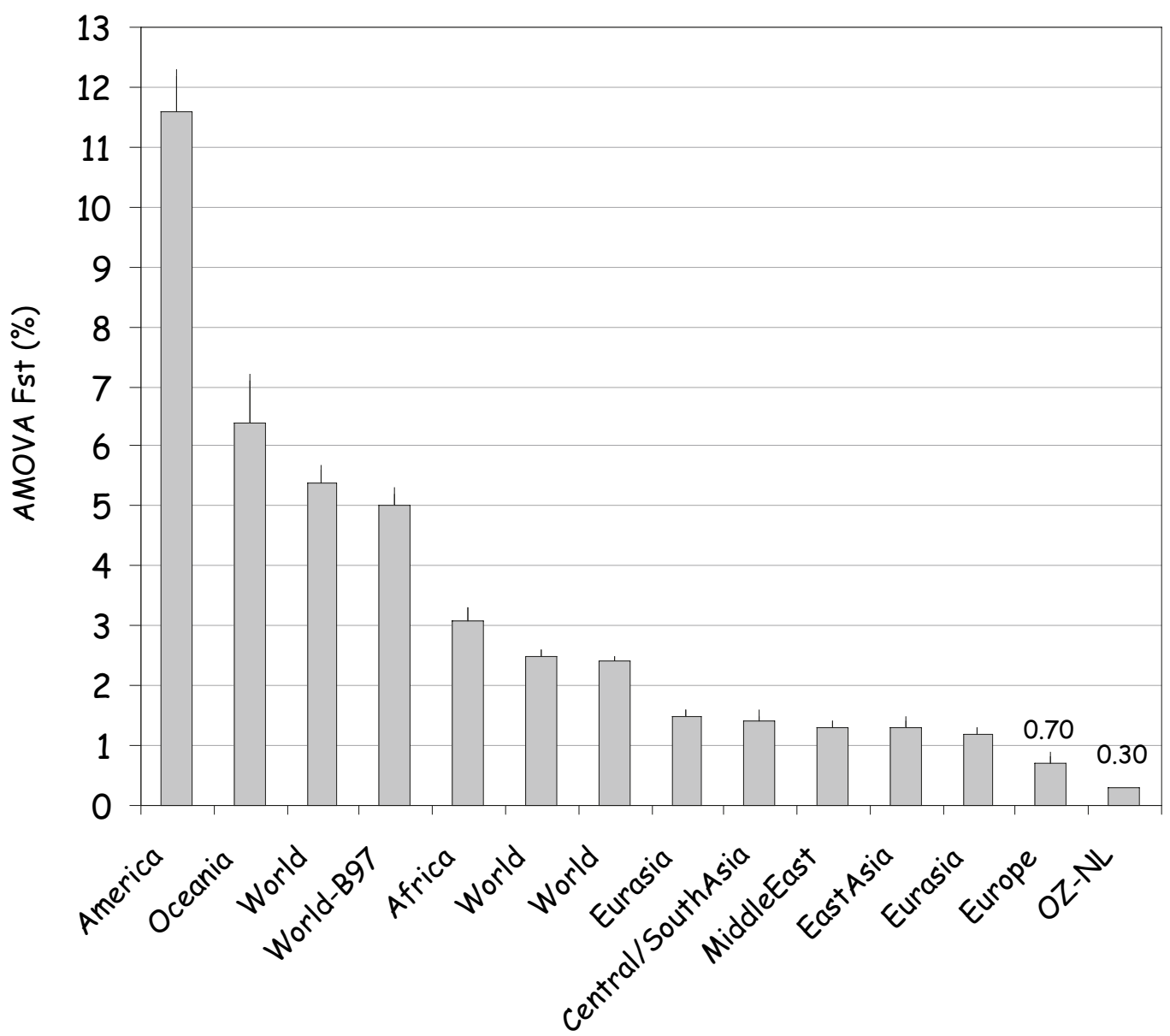

Figure 1

Comparison of $F_{\text {st }}$ values in multiple worldwide cohorts.

Note: The result from this study is at the extreme right. All other data plus $95 \%$ confidence intervals are from (Rosenberg et al., 2002) and are based on 377 autosomal markers. The $y$-axis shows the empirical $F_{\text {st }}$ values as percentages.

Netherlands samples for joint genetic analyses. This finding is not unexpected given the population history of Australia, whose large-scale colonization in the past 250 years was overwhelmingly via immigrants from northern European (mainly from Britain and Ireland) as well as prior empirical results (Stankovich et al., 2006).

An essential caveat is that results such as these do not provide proof the comparability of cohorts, nor do they provide protection against all forms of bias. For example, across cohorts, there may be systematic differences in etiologically relevant environmental exposures, phenotypic assessments, or laboratory procedures. In addition, even if STRP marker patterns are relatively similar in closely related cohorts, empirical data suggest that population stratification can still exert a profound impact at least in some instances (Campbell et al., 2005; Marchini et al., 2004).

\section{Acknowledgments}

We thank Peter Visscher, PhD, for his helpful comments. This work was supported by NIMH grant MH059160 and MH074027.

\section{References}

Boomsma, D. I., Beem, A. L., van den Berg, M., Dolan, C. V., Koopmans, J. R., Vink, J. M., de Geus, E. J., \& Slagboom, P. E. (2000). Netherlands twin family study of anxious depression (NETSAD). Twin Research, 3, 323-334.

Campbell, C. D., Ogburn, E. L., Lunetta, K. L., Lyon, H. N., Freedman, M. L., Groop, L. C., Altshuler, D., Ardlie, K. G., \& Hirschhorn, J. N. (2005). Demonstrating stratification in a European American population. Nature Genetics, 37, 868-872.

Ghebranious, N., Vaske, D., Yu, A., Zhao, C., Marth, G., \& Weber, J. L. (2003). STRP screening sets for the human genome at $5 \mathrm{cM}$ density. BMC Genomics, 4, 6.

Kirk, K. M., Birley, A. J., Statham, D. J., Haddon, B., Lake, R. I. E., Andrews, J. G., \& Martin, N. G. (2000). Anxiety and depression in twin and sib pairs extremely discordant and concordant for neuroticism: Prodromus to a linkage study. Twin Research, 3, 299-309.

Marchini, J., Cardon, L. R., Phillips, M. S., \& Donnelly P. (2004). The effects of human population structure on large genetic association studies. Nature Genetics, 36, 512-517. 
Rosenberg, N. A., Pritchard, J. K., Weber, J. L., Cann, H. M., Kidd, K. K., Zhivotovsky, L. A., \& Feldman, M. W. (2002). Genetic structure of human populations. Science, 298, 2381-2385.

Schneider, S., Roessli, D., \& Excoffier, L. (2001). Arlequin: A software for population genetics data analysis (3.0 ed.) [Computer software]. Geneva, Switzerland: University of Geneva.
Stankovich, J., Cox, C. J., Tan, R. B., Montgomery, D. S., Huxtable, S. J., Rubio, J. P., Ehm, M. G., Johnson, L., Butzkueven, H., Kilpatrick, T. J., Speed, T. P., Roses, A. D., Bahlo, M., \& Foote, S. J. (2006). On the utility of data from the International HapMap Project for Australian association studies. Human Genetics, 119, 220-222.

Weir, B. S., \& Hill, W. G. (2002). Estimating F-statistics. Annual Review of Genetics, 36, 721-750. 